University of Nebraska - Lincoln

DigitalCommons@University of Nebraska - Lincoln

\title{
Comparison of Three Methods of Size Grading Channel Catfish Stockers
}

\author{
Bartholomew W. Green \\ USDA, Agricultural Research Service, bart.green@usda.gov \\ David L. Heikes \\ University of Arkansas at Pine Bluff \\ Andrew E. Goodwin \\ University of Arkansas at Pine Bluff
}

Follow this and additional works at: https://digitalcommons.unl.edu/usdaarsfacpub

Part of the Agriculture Commons, and the Aquaculture and Fisheries Commons

Green, Bartholomew W.; Heikes, David L.; and Goodwin, Andrew E., "Comparison of Three Methods of Size Grading Channel Catfish Stockers" (2004). Publications from USDA-ARS / UNL Faculty. 2478.

https://digitalcommons.unl.edu/usdaarsfacpub/2478

This Article is brought to you for free and open access by the U.S. Department of Agriculture: Agricultural Research Service, Lincoln, Nebraska at DigitalCommons@University of Nebraska - Lincoln. It has been accepted for inclusion in Publications from USDA-ARS / UNL Faculty by an authorized administrator of DigitalCommons@University of Nebraska - Lincoln. 


\title{
Comparison of Three Methods of Size Grading Channel Catfish Stockers
}

\author{
BARTHOLOMEW W. GREEN* \\ Aquaculture Systems Research Unit, \\ U.S. Department of Agriculture, Agricultural Research Service, \\ 1200 North University Drive, Pine Bluff, Arkansas 71601, USA \\ David L. Heikes And Andrew E. Goodwin \\ Aquaculture and Fisheries Center, University of Arkansas at Pine Bluff, \\ 1200 North University Drive, Pine Bluff, Arkansas 71601, USA
}

\begin{abstract}
The stocking of size-graded catfish into production ponds should increase production efficiency, but grading large numbers of fish with existing technology is laborious. We evaluated the effectiveness of a mechanical grader recently developed at the University of Arkansas at Pine Bluff (UAPB) relative to that of box and sock graders and assessed injuries sustained by stocker channel catfish Ictalurus punctatus during grading. Three 0.25 -acre ponds were stocked at 11,777 lb/acre. Initial total length (TL) ranged from 6.3 to $15.7 \mathrm{in}$, and initial weight of individuals ranged from 0.04 to $1.10 \mathrm{lb}$. The fish population in each pond was divided into three groups graded with the box grader, UAPB grader, or sock grader. Fish were graded twice with the box and UAPB graders; a bar spacing of $1 \frac{3 / 32}{3}$ in was used to grade off small fish and a spacing of $13 / 8$ in to grade off large fish. Sock grader mesh size was $1 \frac{3}{8}$ in. Mean weights and lengths of the size-classes produced by grading (small, medium, and large) were compared to those of the initial population in each pond. Blood samples were collected from sampled fish, and serum was analyzed for creatine phosphokinase (CPK) and lactate dehydrogenase (LDH) activities to assess fish injury levels. Each grader separated the initial population into distinct populations. Mean weight and TL of the medium size-class was significantly lower for the UAPB grader than for the box grader. The frequency distributions of the fish populations obtained from each grader differed significantly. Undergrade and overgrade error for the medium size-class did not differ significantly between the box and UAPB graders. Undergrade error averaged $5.4 \%$ for TL and $1.6 \%$ for individual weight; overgrade error averaged $7.8 \%$ for TL and $10.3 \%$ for weight. Serum CPK and LDH activities were highly variable, which prevented detection of significant treatment differences.
\end{abstract}

There is increasing interest in stocking production ponds for channel catfish Ictalurus punctatus with stocker-size $(0.06-0.75 \mathrm{lb})$ fish because they may compete better for feed with carry-over fish, thereby attaining within one season the larger minimum weight now required by processing plants (Pomerleau and Engle 2003; Green and Engle 2004). Channel catfish fingerlings and stockers are sold either by length or by weight, and pond-stocking recommendations are based on length. Grading of fish into defined size-groups before stocking reduces size variation present in the fish population until harvest, reduces the number of submarketable fish present at harvest, and improves farmers' ability to census the fish population accurately (Huner et al. 1984; Busch 1985; Jensen 1990; Carmichael 1994). Two common methods used by farmers to separate fingerlings and stockers by size

\footnotetext{
* Corresponding author: bgreen@spa.ars.usda.gov

Received December 22, 2003; accepted March 26, 2004
}

are passive, in-pond sock grading and box grading (Huner et al. 1984; Jensen 1990).

Mechanical catfish graders were first designed nearly 50 years ago, and the design was modified 20 years later (Morton 1956; Greenland and Gill 1972; Greenland et al. 1972; Theis and Sears 1976). However, the use of mechanical graders to separate channel catfish into distinct size-classes has met with mixed success, in part because catfish extend and lock their pectoral spines when handled or removed from water, which results in ineffective size grading (Busch 1985). An in-pond mechanical grader was recently developed at the University of Arkansas at Pine Bluff (UAPB) to expedite size grading of fish. The UAPB grader is composed of three major components: a floating, adjustable, horizontal bar grader, a trailer with a built-in power-take-off (PTO) driven water pump, and an eductor system that delivers fish to the grading surface. Fish landed in a live car are crowded into the eductor box, then pumped through a tube onto the grading surface. Fish retained by the grader 
swim the entire length of the grader and into a second live car, while smaller fish swim down through the bars and are collected in a live car or returned to the pond.

In addition to cost, speed, and accuracy, factors used evaluate grading methods include fish injury and stress (Grizzle et al. 1992). Negative feedback caused by stress-induced hormone production can result in reduced fish growth (Pickering 1993). The benefit gained from the size grading of fish populations must be balanced against the stress response and injuries sustained, and their potential impacts on fish growth. Increased serum cortisol and glucose concentrations and decreased serum chloride concentration are among the measurable stress responses in fish (Carmichael et al. 1984a, 1984b). Because our experimental design made it difficult to measure these time-critical aspects of the stress response, we instead measured serum proteins that provide direct evidence of damage to muscles and internal organs. Serum aspartate aminotransferase and lactate dehydrogenase (LDH) activities have been used as indicators of injury experienced by fish during handling (Grizzle et al. 1992; Grizzle and Lovshin 1994, 1996). The creatine phosphokinase (CPK) enzyme is found in the muscles and brains of animals; serum CPK activity is elevated following damage to these organs (Bentinck-Smith et al. 1987). The CPK and LDH enzymes normally are not present in fish blood; however, when a fish is bruised, banged, or squeezed, these proteins leak out of damaged cells and into the blood, where they can be measured and used as indicators of tissue damage.

The ability to select a specific size range of channel catfish would be advantageous given the wide range in individual weight $(0.06-0.75 \mathrm{lb})$ and total length (TL; 6-13 in) of stockers. Our objectives were to compare the efficiency of the UAPB grader to that of two existing grading methods and to compare injuries sustained by channel catfish stockers graded by the three methods.

\section{Methods}

Three 0.25 -acre earthen ponds located at the Aquaculture Research Station, UAPB, were used for this study. A 0.5-hp electric paddlewheel aerator was operated nightly in each pond to maintain dissolved oxygen concentrations greater than 3.0 ppm. Ponds were stocked with channel catfish at $11,777 \mathrm{lb} /$ acre during the period 23 May to 15 June 2001. Fish were fed an average of $73.6 \mathrm{lb} / \mathrm{acre}$ of floating extruded feed ( $32 \%$ crude protein) on each of $30 \mathrm{~d}$ during 1 June to 8 July 2001. The grading trial was conducted over three 2 -d periods between 12 July and 19 July 2001. Mean pond water temperatures ranged from $83.8^{\circ} \mathrm{F}$ to $91.6^{\circ} \mathrm{F}$. Each pond was assigned randomly to a 2 -d grading trial period. Fish were not fed during the grading trial.

Three graders were tested during each trial: an in-pond grader net (sock grader), the UAPB inpond mechanical grader, and a box grader. The fish population in each pond was captured by seine and concentrated into a 3/8-in mesh live car $(8 \times 30$ $\times 4 \mathrm{ft}$ ). Fish in the live car were crowded, and a random sample of 100 fish was collected. Fish in the sample were weighed individually to the nearest $0.01 \mathrm{lb}$ and measured to the nearest 0.1 in to establish the initial size distribution. The fish population in the live car was then divided into three groups subjected to one of the three grading procedures. All three groups were graded on the same day.

A mean of $1,160 \mathrm{lb}$ of fish from the live car in each pond was graded with the UAPB grader. A two-step grading process was required to obtain a medium size-class of fish. A grader bar spacing of $13 / 8$ in was used to remove the large size-class, and then a bar spacing of $13 / 32$ in was used to separate the medium size-class from the small size-class. Fish of each size-class were collected in separate live cars as they exited the grader.

Another group of fish was sorted with a sock grader. It is difficult to scale down a commercial catfish grader net to a size convenient for 0.25 acre research ponds while still maintaining commercial grader net loading rates in terms of pounds per cubic foot of net volume and pounds per square foot of vertical grading surface. Therefore, a 4-ftdiameter, $1 / 4$-in-mesh floating live net was modified to simulate the minimum loading rate recommended by a commercial sock grader manufacturer (Delta Net and Twine Co., Greenville, Mississippi). A 3.34-linear-foot section of the live net's vertical netting was replaced with $13 / 8$ in mesh netting. The modified floating live net was placed inside a $8 \times 40 \times 4 \mathrm{ft}, 0.25$-in-mesh live car and loaded with a mean of $785 \mathrm{lb}$ of fish dipped at random from the live car in each pond. The loading rate was $17.1 \mathrm{lb} / \mathrm{ft}^{3}$ of live-net volume and $64 \mathrm{lb} / \mathrm{ft}^{2}$ of live-net grading surface. Fish were allowed to grade passively for approximately $24 \mathrm{~h}$.

The third group of fish was sorted with floating box graders. Two box graders $(39 \times 24 \times 11$ in $)$ were used: one was fitted with a number-70 basket $(13 / 32$-in bar spacing) and the other was fitted with a number- 88 basket ( $13 / 8$-in bar spacing). A mean of $794 \mathrm{lb}$ of fish were dipped at random from the 
TABLE 1.-Mean \pm SD individual weights and total lengths (TL) of channel catfish populations before and after size grading with box graders, a sock grader, or a grader developed at the University of Arkansas at Pine Bluff (UAPB). Valid comparisons within columns are among means within a population or grader type and between these means and the initial population. Means followed by the same letter are not significantly different $(P>0.05)$.

\begin{tabular}{lllr}
\hline \multicolumn{1}{c}{ Population } & Grader type & Weight (lb) & TL (in) \\
\hline Initial & & $0.24 \pm 0.02 \mathrm{xt}$ & $10.0 \pm 0.3 \mathrm{xu}$ \\
Small fish & Box & $0.15 \pm 0.02 \mathrm{u}$ & $8.7 \pm 0.1 \mathrm{v}$ \\
& UAPB & $0.13 \pm 0.01 \mathrm{u}$ & $8.4 \pm 0.1 \mathrm{v}$ \\
Medium fish & Box & $0.36 \pm 0.01 \mathrm{w}$ & $11.2 \pm 0.1 \mathrm{w}$ \\
& UAPB & $0.29 \pm 0.01 \mathrm{v}$ & $10.6 \pm 0.2 \mathrm{x}$ \\
Large fish & Box & $0.63 \pm 0.05 \mathrm{z}$ & $13.2 \pm 0.2 \mathrm{z}$ \\
& UAPB & $0.54 \pm 0.04 \mathrm{z}$ & $12.6 \pm 0.5 \mathrm{z}$ \\
& Sock & $0.40 \pm 0.05 \mathrm{y}$ & $11.7 \pm 0.3 \mathrm{y}$ \\
Residual after topping & Box & $0.26 \pm 0.01 \mathrm{t}$ & $9.9 \pm 0.1 \mathrm{u}$ \\
& UAPB & $0.22 \pm 0.01 \mathrm{sx}$ & $9.5 \pm 0.1 \mathrm{tu}$ \\
& Sock & $0.20 \pm 0.02 \mathrm{~s}$ & $9.2 \pm 0.3 \mathrm{t}$ \\
\hline
\end{tabular}

live car in each pond and transported to a concrete vat $(4 \times 17 \times 3 \mathrm{ft})$ for grading with the box graders. Three additional vats, supplied with diffused air and water exchange, were used during the grading. Fish were graded first through the number-70 grader to remove the small size-class and then through the number- 88 grader to separate the medium size-class from the large size-class.

A random sample of 100 fish per size-class (small, medium, or large) was collected by each grader upon completion of grading. Fish were weighed and measured individually, and least squares analysis was used to fit a curve to the data $(n=2,700)$. Time was measured for each phase of the grading process, beginning when fish were moved out of the live car and ending when the fish were returned to the pond.

Blood samples were collected from fish in each replicate and analyzed for CPK and LDH. Twentyfive fish were selected at random from the initial population and from the target size-classes produced by each grader type. Blood collected from the caudal vein was placed on ice for $30 \mathrm{~min}$ and centrifuged at $2,000 \times$ gravity for $10 \mathrm{~min}$, and then serum was frozen at $-112^{\circ} \mathrm{F}$ until analysis. Enzyme activity was assayed with commercial kits for CPK (Sigma 520-C) and LDH (Sigma 500-C).

Grading was evaluated in several ways. Small and medium size-classes from the box and UAPB graders were compared directly and with the initial population. The large size-class, obtained when the fish population was topped (selectively harvested for large fish), was compared among all three grader types and with the initial population. The residual population after topping also was compared among all three graders and with the initial population; for this comparison, the small and medium size-classes from the box and UAPB graders were combined. The split point, which is the TL group or weight-class at which the graded population can be divided into equal proportions, was determined for each grader. Undergrade error (the percentage of fish that should pass through the grader but do not) and overgrade error (the percentage of fish that should not pass through the grader but do) were measured for each grader type based on the corresponding split points.

Data were subjected to analysis of variance and Tukey's Studentized range test (Sokal and Rohlf 1995) in the Statistical Analysis System (SAS) software (Muller and Fetterman 2002). Percentage data were arcsine-transformed prior to analysis (Sokal and Rohlf 1995). Length- and weight-frequency distributions were analyzed by use of the Mantel-Haenszel chi-square statistic in SAS. The Mantel-Haenszel analysis was indicated because its assumptions require subjects to be randomized to levels of the row variable, and sample size is based on total frequencies instead of individual cell sizes (Stokes et al. 2000). Skewness and kurtosis were determined by the univariate procedure in SAS. Statistical comparison of labor time required for each grader type was deemed inappropriate because of the substantial procedural differences among grader types. The significance level $\alpha$ for all tests was 0.05 .

\section{Results}

\section{Mean Weight and Length}

Fish in the initial population averaged $0.24 \mathrm{lb}$ and 10.0 in TL (Table 1). The box and UAPB graders separated fish into three size-classes (small, medium, or large), whereas the sock grader separated fish into either large or small and medium combined (residual) after topping of size- 
TABLE 2.-Split points in total length (TL) group or weight-class for a population of stocker channel catfish that was graded with box, a sock grader, or the in-pond grader developed at the University of Arkansas at Pine Bluff (UAPB). Large fish were graded off by use of $13 /$ 8 -in mesh/bar spacing. Small fish were graded off by use of $13 / 32$-in bar spacing (box and UAPB graders only).

\begin{tabular}{|c|c|c|c|c|}
\hline \multirow[b]{2}{*}{$\begin{array}{l}\text { Grader } \\
\text { type }\end{array}$} & \multicolumn{2}{|c|}{$13 / 32$-in spacing } & \multicolumn{2}{|c|}{$13 / 8$-in spacing } \\
\hline & $\begin{array}{l}\text { TL group } \\
\text { (in) }\end{array}$ & $\begin{array}{c}\text { Weight-class } \\
\text { (lb) }\end{array}$ & $\begin{array}{l}\text { TL group } \\
\text { (in) }\end{array}$ & $\begin{array}{c}\text { Weight-class } \\
\text { (lb) }\end{array}$ \\
\hline Box & 10.0 & 0.23 & 12.4 & 0.47 \\
\hline UAPB & 9.6 & 0.19 & 11.8 & 0.39 \\
\hline Sock & & & 10.8 & 0.27 \\
\hline
\end{tabular}

classes (Table 1). After grading, the mean weight and TL of the small size-class for each grader type were significantly lower than those of the initial population. The mean weight and TL of the medium size-class were significantly smaller for the UAPB grader than for the box grader. The large size-classes obtained with the box and UAPB graders had similar mean weights and TLs, and were significantly heavier and longer than the large sizeclass obtained with the sock grader.

The mean weight of residual fish after topping was significantly greater for the box grader than for the UAPB or sock graders, and the mean weight of residual fish for the box grader was not different from the mean weight of the initial population (Table 1). Mean TL of residual fish after topping did not differ between the box and UAPB graders or between these two grader types and the initial population.

The stocker catfish population used in this study ranged from 5 to 16 in TL. The relationship between individual weight ( $W$ ) and TL for this population was described by the equation $W=$ $0.0000835 \times \mathrm{TL}^{3.44059}\left(r^{2}=0.99\right)$.

\section{Split Point}

Split points by length-group or weight-class for the three grader types are shown in Table 2. The split points for TL at both levels of bar spacing were $4-5 \%$ higher for the box grader compared to the UAPB grader. Box grader weight-class split points were $15-24 \%$ higher than split points for the UAPB grader. The TL split point was $9-15 \%$ lower and the weight-class split point was $44-74 \%$ lower for the sock grader than for the box and UAPB graders. The difference between the two TL split points was 2.4 in for the box grader and 2.2 in for the UAPB grader. The difference between weight-class split points was $0.24 \mathrm{lb}$ for the box grader and $0.20 \mathrm{lb}$ for the UAPB grader.

\section{Overgrade and Undergrade Errors}

Mean TL undergrade error did not differ significantly between graders and was $2.9 \%$ and of the population for the box grader and $7.8 \%$ for the UAPB grader. Total length overgrade error was not significantly different, averaging $8.6 \%$ for the box grader and $7.0 \%$ for the UAPB grader. Weightclass undergrade error was low for both grader types, averaging $1.3 \%$ for the box grader and $1.8 \%$ for the UAPB grader. Weight-class overgrade error averaged $12.2 \%$ for the box grader and $8.3 \%$ for the UAPB grader; the values for the two grader types did not differ significantly.

\section{Length- and Weight-Frequency Distributions}

Frequency distributions for TL and weight were not normally distributed and differed among sizeclasses and graders. The TL and weight distributions for the medium size-class differed significantly between the box and UAPB graders (Figures 1,2$)$. Mean skewness of the TL and weight distributions for the medium size-class were 0.192 and 0.798 , respectively, for the box grader and 0.212 and 0.798 , respectively, for the UAPB grader and did not differ significantly among treatments. Kurtosis of the TL and weight distributions for the medium size-class averaged -0.306 and 0.535 , respectively, for the box grader and -0.565 and 0.720 , respectively, for the UAPB grader. Mean kurtosis for the TL distribution differed significantly between the box and UAPB graders.

Length- and weight-frequency distributions for the large size-class (Figures 3,4) and the residual size-class differed significantly among grader types. Mean skewness of the TL distribution for large size-class was 0.587 for the box grader, 0.001 for the UAPB grader, and 0.118 for the sock grader, and did not differ significantly among treatments. Kurtosis of the TL distribution for the large sizeclass did not differ among grader types, and averaged 1.041 for the box grader, 0.050 for the UAPB grader, and 0.584 for the sock grader. Weight distributions for the large size-class had mean skewness values of 1.060 for the box grader, 0.628 for the UAPB grader, and 1.075 for the sock grader; mean kurtosis was 2.096, 0.193, and 1.575 for the box grader, UAPB grader, and sock grader, respectively. No significant differences in large size-class distribution were detected among graders.

\section{Fish Injury Indicators}

Serum CPK and LDH activities were highly variable among replicates and treatments, and no sig- 

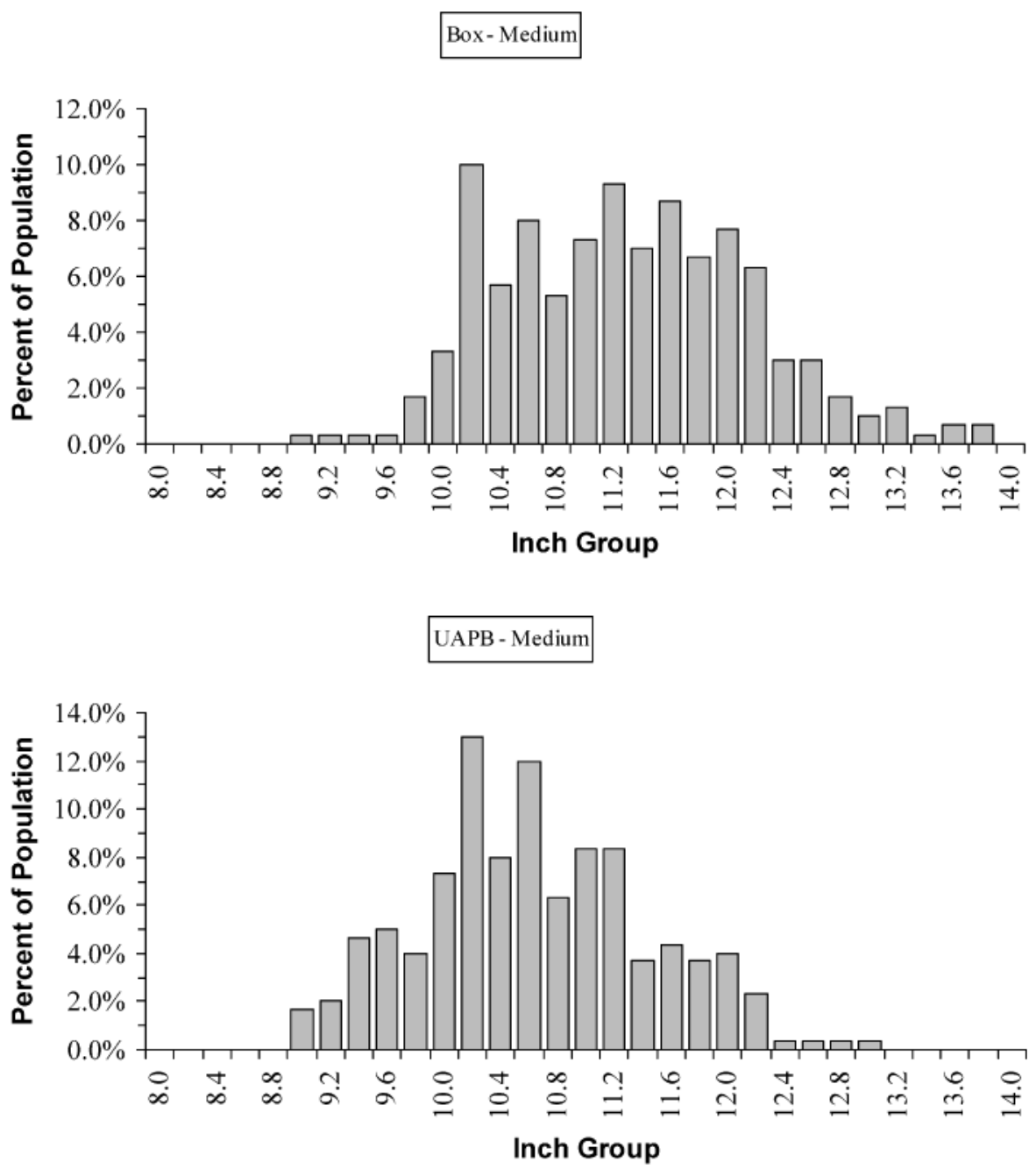

FIGURE 1.-Frequency distributions of channel catfish total lengths in the medium size-class obtained with a box grader or a mechanical in-pond grader developed at the University of Arkansas at Pine Bluff (UAPB). Bar

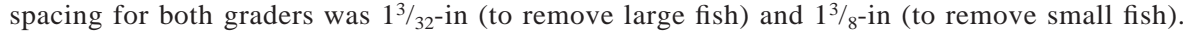

nificant treatment differences were detected. Mean CPK activity ranged from 1,978 to $3,139 \mu \mathrm{mol}$ of substrate utilized per minute per liter of serum, and mean LDH activity ranged from 361 to 765 $\mu$ mol of substrate utilized per minute per liter of serum.

\section{Grading Time Requirements}

The time required for grading and for the grading process (e.g., equipment set-up, fish transfers, etc) varied among grader types. Passive grading with the sock grader took $24 \mathrm{~h}$, yielding a mean grading rate of $0.6 \mathrm{lb}$ of fish/min, but the fish were graded only once, not twice like in the other methods. However, only about $1 \mathrm{~h}$ of additional labor time was required beyond seining to load fish into and out of the sock. The box grader method required 27-45 min for grading and 127-169 min for process time beyond seining. Box graders achieved a grading rate of $17-30 \mathrm{lb} / \mathrm{min}$. From 50 to 112 min of labor beyond seining was required for the UAPB grader. The UAPB grader required 19-27 $\mathrm{min}$ of grading time, which equaled a grading rate of $50-76 \mathrm{lb} / \mathrm{min}$. The quantity of fish graded with the UAPB grader increased after the first replicate, and the process time required decreased with each subsequent replicate. 


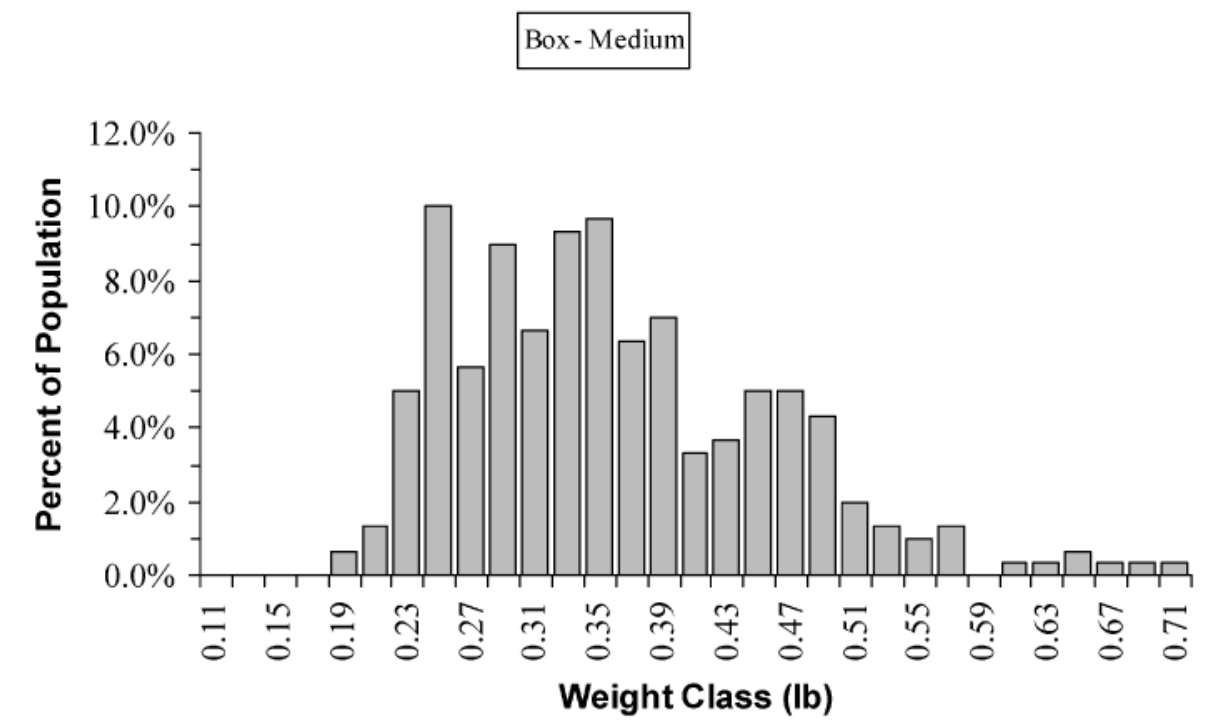

UAPB - Medium

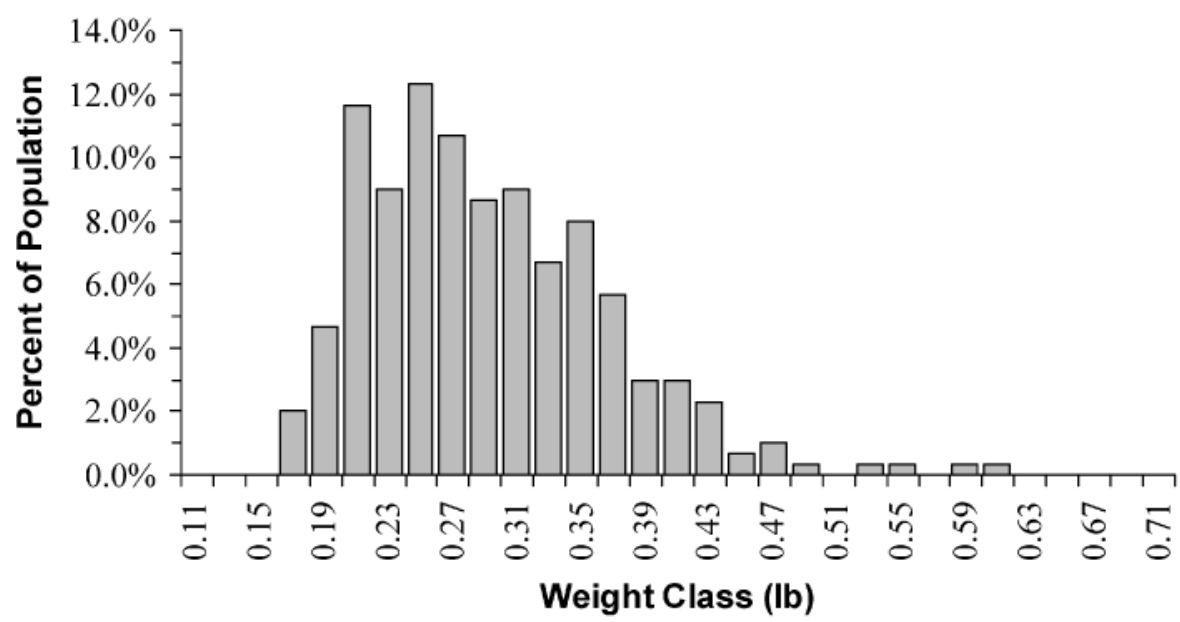

FIGURE 2.-Frequency distributions of individual weights of channel catfish in the medium size-class obtained with a box grader or a mechanical in-pond grader developed at the University of Arkansas at Pine Bluff (UAPB). For both graders, bar spacing was $1 \frac{3 / 32}{3}$ in to grade off small fish and $1 \frac{3 / 8}{8}$ in to grade off large fish.

\section{Discussion}

Each grader separated the initial channel catfish population into distinct subpopulations. Fish used in this experiment were lighter than fish grown under commercial conditions in Mississippi (Steeby et al. 1991), which affected the results of grading. In the present experiment, the population graded through $13 / 32$-in bar spacing was split at 9.6-10.0 in TL and $0.19-0.23 \mathrm{lb}$, in contrast to the split points of $8.6 \mathrm{in}$ TL and $0.19 \mathrm{lb}$ expected for a fish population in good condition. Grading fish through $13 / 8$-in bar spacing or mesh size yielded split points of 10.8-12.4 in TL and $0.27-0.47 \mathrm{lb}$ compared to the split points of 10.2 in TL and 0.34 $\mathrm{lb}$ expected for a population in good condition. Thus, the presence of underweight fish in the initial population shifted the split points for TL and weight to higher size-classes compared with standardized grading charts. Fish condition clearly affected grading in our study. 
Box - Large

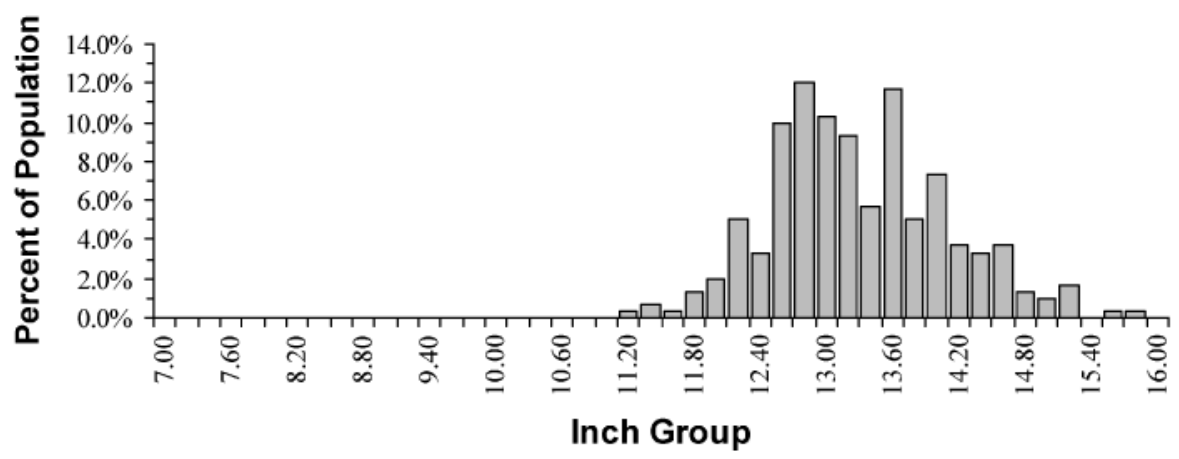

UAPB - Large

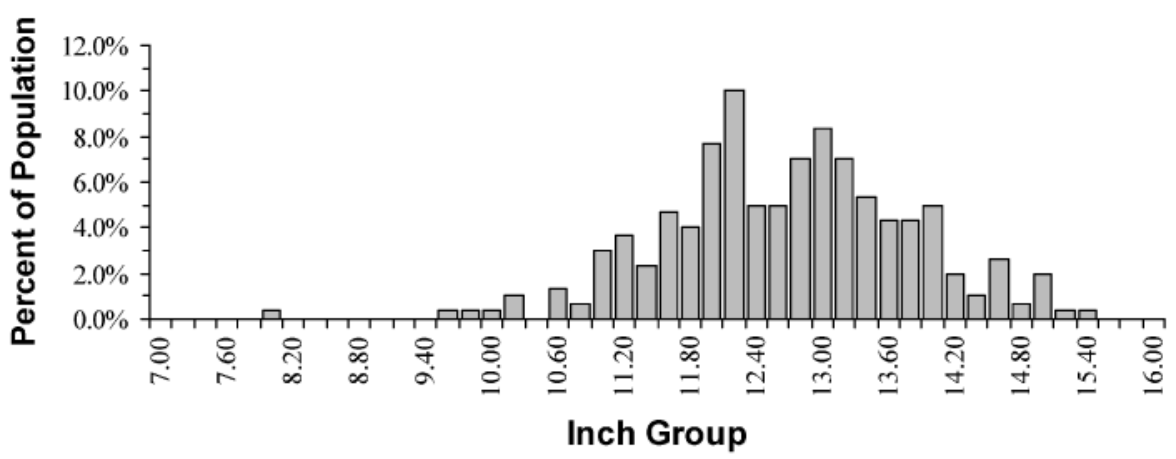

Sock - Large

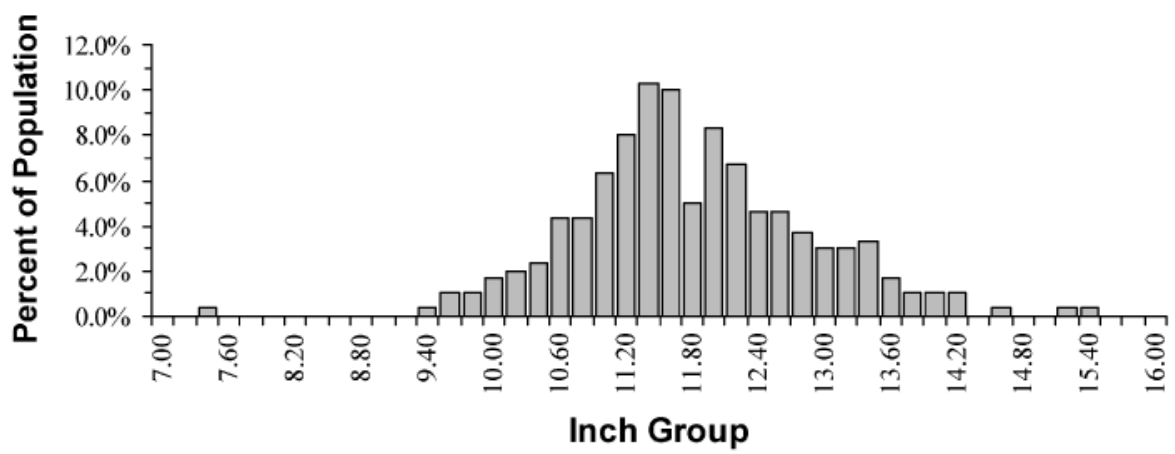

FIGURE 3.-Frequency distributions of channel catfish total lengths in the large size-class obtained with a box grader, a mechanical in-pond grader developed at the University of Arkansas at Pine Bluff (UAPB), or a sock grader. Graders were equipped with a $1 \frac{3}{8}$-in bar spacing or mesh size.

A benefit of the box grader and UAPB grader methods is that the size range of the graded fish can be assessed during the grading process. These two grader types can be adjusted if one or more factors (e.g., fish condition) affect grading. Box grader baskets are changed easily and are available in a variety of bar spacing. However, the appropriate baskets must be available readily. The UAPB grader's bar spacing is controlled manually without the need for additional parts or tools. 
Box - Large

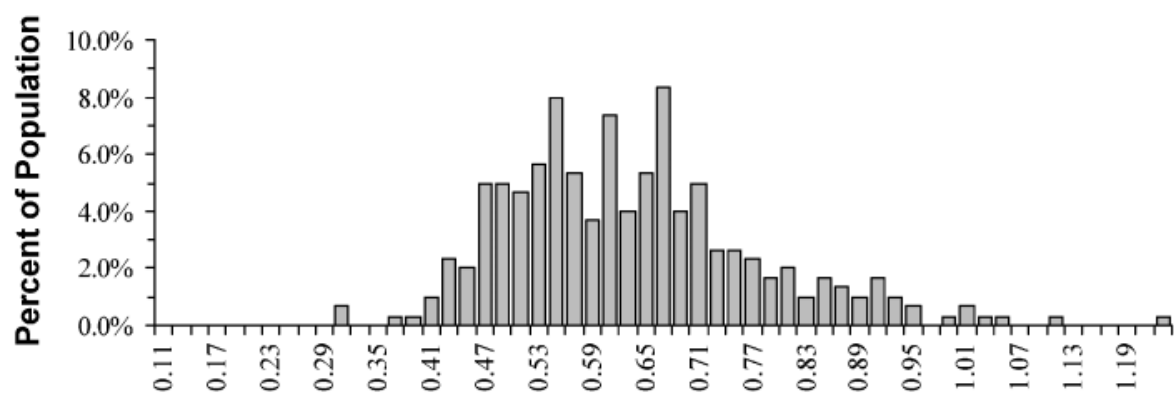

Weight Class (lb)

\section{UAPB - Large}

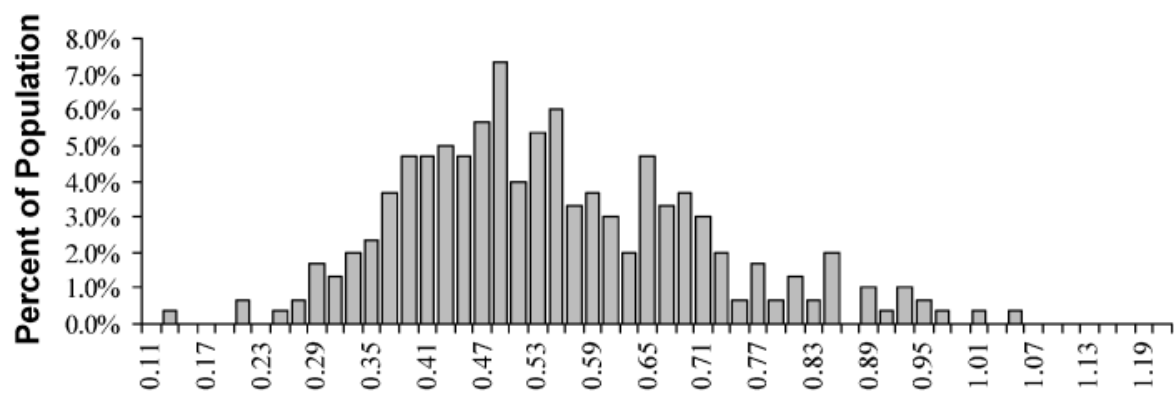

Weight Class (lb)

Sock - Large

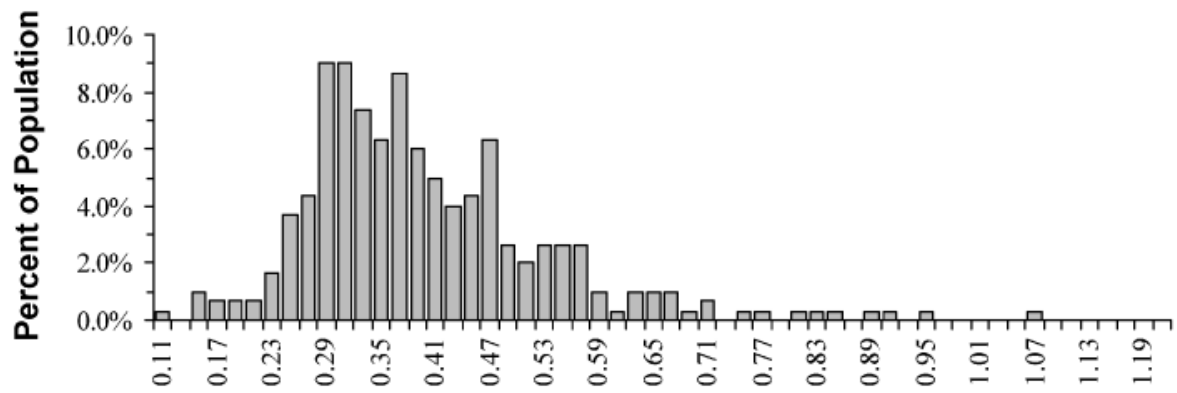

Weight Class (lb)

FIGURE 4.-Frequency distributions of individual weights of channel catfish in the large size-class obtained with a box grader, a mechanical in-pond grader developed at the University of Arkansas at Pine Bluff (UAPB), or a sock grader. Graders were equipped with a $1 \frac{3}{8}$-in bar spacing or mesh size.

The box and UAPB graders can be used to select a defined size range from a given population by grading the fish to remove large and small individuals. However, at the bar spacing used in the present trial, the selected fish population (i.e., the medium size-class) obtained with the UAPB grader was significantly lighter and shorter than the fish obtained with the box grader. Therefore, the bar spacing on the UAPB grader would need to be increased slightly to obtain a target fish population 
similar to that obtained by box grading. The exact amount of the increase in bar spacing must be determined empirically and will be dependent on grading conditions, including the condition of the fish population.

Though TL and weight undergrade and overgrade errors were observed for the medium sizeclass produced by both the box and UAPB graders, the magnitude of these errors did not differ significantly between grader types. Relatively small quantities of fish were graded in the present experiment, which may affect the undergrade and overgrade errors for the UAPB grader. Data from field trials on commercial farms indicate that grading errors with the UAPB grader are most likely to occur when the grading panel is less than fully loaded (D. Heikes, UAPB, unpublished data). With the substantially higher fish biomass $(>10,000 \mathrm{lb})$ typically graded under commercial farm conditions, the overall grading error is diminished. This is because the grader panel remains fully loaded for a greater proportion of the grading process.

All three graders can be used to grade large fish from a population (i.e., to top the population) in a pond. The box and UAPB graders yielded large fish that did not differ significantly in mean individual weight or TL. However, the large sizeclass obtained with the sock grader had significantly lower mean individual weight and TL compared to the other two grader types.

Both the box grader and the UAPB grader utilize an active grading process in which fish are physically in contact with the grading surface and the fish population is graded twice, once to remove smaller fish and once to remove larger fish. Grading fish with the sock grader is a passive process, and the fish population is graded only once. Additional factors that affect grading efficiency include water temperature, duration, loading rate, the size range of the fish population, and operating conditions (Tucker and Robinson 1990). Water temperatures during the present experiment were favorable for grading, ranging from $83.8^{\circ} \mathrm{F}$ to $91.6^{\circ} \mathrm{F}$. Even when water temperatures are warm, fingerling producers generally allow fish to grade overnight (Tucker and Robinson 1990).

Time and labor are two additional factors to consider in selecting a grading method. The most common method of grading fish in ponds is the sock grader (Tucker and Robinson 1990), although it can require the longest time period. In our study, only about $1 \mathrm{~h}$ of additional labor was required for the sock-grading process beyond seining. Low water temperature limits use of the sock grader be- cause grading efficiency is poor and appears independent of the time fish are confined in the sock (Tucker and Robinson 1990). Furthermore, in order to split the fish population two ways, as was done with the box and UAPB graders, the pond must be seined twice and the fish must be sockgraded twice, which requires substantially more time and labor. This method may result in increased grading error because the second grading is not performed on a confined, graded population.

Less time was required for fish grading and the associated process with the UAPB grader than with the box grader. Because the UAPB grader is operated in-pond, transport time is reduced. Process time required for the UAPB grader decreased with each subsequent replicate. Data from field trials of the UAPB grader on commercial fish farms indicate that large biomasses $(>10,000 \mathrm{lb})$ are graded at rates in excess of $400 \mathrm{lb} / \mathrm{min}$ (D. Heikes, UAPB, unpublished data). In a study that evaluated a mechanical V-belt-style grader, Lovshin and Phelps (1993) reported that fish were graded at a rate of $26 \mathrm{lb} / \mathrm{min}$. Operation of the UAPB grader, in particular, requires a certain degree of skill, and performance will improve with practice until the operators are fully proficient.

High individual variability in serum CPK and LDH activities was responsible for our inability to detect significant treatment differences. This high variation probably reflects the varied experiences of fish as they go through the grading process, with the differences in those experiences within a grading method outweighing the differences between methods.

In summary, the box grader, UAPB grader, and sock grader were effective in separating 6.3-15.7in-TL stocker channel catfish into defined sizeclasses. Fish populations were divided into three size-classes by the box and UAPB graders and two size-classes by the sock grader. Split points were affected by fish condition. Undergrade and overgrade errors were similar for the box and UAPB graders when the fish population was graded twice to select the medium size-class. Throughput of graded fish $(\mathrm{lb} / \mathrm{min})$ was higher with the UAPB grader than with the other two grader types. High individual variability in enzyme response masked any effect that grading might have had on tissue damage. The box and UAPB graders were effective at splitting the stocker channel catfish population to obtain a defined size-class, and therefore would be appropriate for situations in which a small biomass of fish is to be graded. 


\section{Acknowledgments}

The authors thank Tom Popham, U.S. Department of Agriculture, Agricultural Research Service, Southern Plains Area, for his assistance with SAS.

\section{References}

Bentinck-Smith, J., M. H. Beleau, P. Waterstrat, C. S. Tucker, F. Stiles, P. R. Bowser, and L. A. Brown. 1987. Biochemical reference ranges for commercially reared channel catfish. Progressive Fish-Culturist 49:108-114.

Busch, R. L. 1985. Harvesting, grading, and transporting. Pages 543-567 in C. S. Tucker, editor. Channel catfish culture. Elsevier Publishers, Amsterdam.

Carmichael, G. J. 1994. Effects of size grading on variation and growth in channel catfish reared at similar densities. Journal of the World Aquaculture Society 25:101-108.

Carmichael, G. J., J. R. Tomasso, B. A. Simco, and K. B. Davis. 1984a. Confinement and water-qualityinduced stress in largemouth bass. Transactions of the American Fisheries Society 113:767-777.

Carmichael, G. J., J. R. Tomasso, B. A. Simco, and K. B. Davis. 1984b. Characterization and alleviation of stress associated with hauling largemouth bass. Transactions of the American Fisheries Society 113: $778-785$.

Green, B. W., and C. R. Engle. 2004. Growth of stocker channel catfish to large market size in single-batch culture. Journal of the World Aquaculture Society 35:25-32.

Greenland, D. C., J. E. Ellis, and R. L. Gill. 1972. Operating and design criteria of an adjustable horizontal bar grader for sorting channel catfish. Progressive Fish-Culturist 34:186-190.

Greenland, D. C., and R. L. Gill. 1972. Development and operation efficiency of a catfish grader. Progressive Fish-Culturist 34:76-80.

Grizzle, J. M., J. Chen, J. C. Williams, and J. S. Spano. 1992. Skin injuries and serum enzyme activities of channel catfish (Ictalurus punctatus) harvested by fish pumps. Aquaculture 107:333-346.

Grizzle, J. M., and L. L. Lovshin. 1994. Effect of pump speed on injuries to channel catfish (Ictalurus punctatus) during harvest with a turbine pump. Aquacultural Engineering 13:109-114.
Grizzle, J. M., and L. L. Lovshin. 1996. Injuries and serum enzyme activities of fingerling channel catfish (Ictalurus punctatus) harvested with a turbine pump. Aquacultural Engineering 15:349-357.

Huner, J. V., H. K. Dupree, and D. C. Greenland. 1984. Harvesting, grading, and holding fish. Pages 158164 in H. K. Dupree and J. V. Huner, editors. Third report to the fish farmers: the status of warmwater fish farming and progress in fish farming research. U.S. Fish and Wildlife Service, Washington, D.C.

Jensen, G. L. 1990. Sorting and grading warmwater fish. U.S. Department of Agriculture, Cooperative State Research, Education, and Extension Service, Southern Regional Aquaculture Center Publication Number 391, Washington, D.C.

Lovshin, L. L., and R. P. Phelps. 1993. Evaluation of a mechanical grader to separate fingerling channel catfish, Ictalurus punctatus, into length groups. Journal of Applied Aquaculture 3:285-296.

Morton, K. E. 1956. A new mechanically adjustable multisize fish grader. Progressive Fish-Culturist 18: 62-66.

Muller, K. E., and B. A. Fetterman. 2002. Regression and ANOVA: an integrated approach using SAS software, version 8.2. SAS Institute, Cary, North Carolina.

Pickering, A. D. 1993. Growth and stress in fish production. Aquaculture 111:51-63.

Pomerleau, S., and C. R. Engle. 2003. Production of stocker-size channel catfish: effect of stocking density on production characteristics, costs, and economic risk. North American Journal of Aquaculture 65:112-119.

Sokal, R. R., and F. J. Rohlf. 1995. Biometry, the principles and practice of statistics in biological research, 3rd edition. Freeman. New York.

Steeby, J. A., R. L. Busch, and C. S. Tucker. 1991. A length-weight relationship for channel catfish grown under commercial conditions in Mississippi. Progressive Fish-Culturist 53:57-60.

Stokes, M. E., C. S. Davis, and G. G. Koch. 2000. Categorical data analysis using the SAS system, 2nd edition. SAS Institute Inc., Cary, North Carolina.

Theis, G. L., and F. W. Sears. 1976. Modified "Morton", fish grader. Progressive Fish-Culturist 38:202-203.

Tucker, C. S., and E. H. Robinson. 1990. Channel catfish farming handbook. Van Nostrand Reinhold, New York. 